Int. J. Electrochem. Sci., 13 (2018) 4390 - 4400

\title{
The Effect of the Substituent Length in Protic Ionic Liquid Additive on the Corrosion Process in the Lead-Acid Battery
}

\author{
Kacper Kopczyński ${ }^{1}$, Agnieszka Gabryelczyk ${ }^{1}$, Marek Baraniak ${ }^{1}$, Bartosz Łęgosz ${ }^{1}$, Juliusz Pernak ${ }^{1}$, \\ Pawet Kędzior ${ }^{2}$, Grzegorz Lota ${ }^{1, *}$ \\ ${ }^{1}$ Faculty of Chemical Technology, Poznan University of Technology, Berdychowo 4, 60-965 Poznan, \\ Poland \\ ${ }^{2}$ PPUH AUTOPART Jacek Bąk Sp. z o.o., Kwiatkowskiego 2a, 39-300 Mielec, Poland \\ *E-mail: grzegorz.lota@put.poznan.pl
}

doi: $10.20964 / 2018.05 .58$

Received: 8 January 2018 / Accepted: 7 March 2018 / Published: 10 April 2018

\begin{abstract}
Modern automotive industry still relies on the lead-acid batteries as a power supply for starting, lighting and ignition applications. In order to provide efficient devices, manufacturers should control the quality and electrochemical properties of the product. One of the disadvantages of the lead-acid batteries is the corrosion process of the current collectors in the lead-acid batteries. In the presented work, an investigation of the influence of the protic ionic liquids on the corrosion process and gas evolution in the lead alloy/sulfuric acid electrochemical system has been conducted. The aim was to correlate the substituent length in the ionic liquid cation with the electrochemical window of the modified electrolytes and corrosion behavior of the lead alloy. Five new compounds were synthesized and their properties as ionic liquids were confirmed using thermogravimetric analysis and differential scanning calorimetry. The techniques used during the electrochemical experiments include linear sweep voltammetry and electrochemical impedance spectroscopy. The obtained results revealed that the electrochemical stability of the electrolytes increases with the length of the substituent. Satisfactory change was observed also in the corrosion behavior of the modified systems.
\end{abstract}

Keywords: Corrosion; hydrogen evolution; side-chain length; current collector; lead-acid battery

\section{FULL TEXT}

(C) 2018 The Authors. Published by ESG (www.electrochemsci.org). This article is an open access article distributed under the terms and conditions of the Creative Commons Attribution license (http://creativecommons.org/licenses/by/4.0/). 